\title{
The ECOMA 2007 campaign: rocket observations and numerical modelling of aerosol particle charging and plasma depletion in a PMSE/NLC layer
}

\author{
A. Brattli ${ }^{1}$, Ø. Lie-Svendsen ${ }^{1}$, K. Svenes ${ }^{1}$, U.-P. Hoppe ${ }^{1}$, I. Strelnikova ${ }^{2}$, M. Rapp ${ }^{2}$, R. Latteck ${ }^{2}$, and M. Friedrich ${ }^{3}$ \\ ${ }^{1}$ Norwegian Defence Research Establishment (FFI), P.O. Box 25, 2027 Kjeller, Norway \\ ${ }^{2}$ Leibniz-Institute of Atmospheric Physics, Kühlungsborn, Germany \\ ${ }^{3}$ Graz University of Technology, Austria
}

Received: 27 October 2008 - Revised: 16 January 2009 - Accepted: 24 January 2009 - Published: 17 February 2009

\begin{abstract}
The ECOMA series of rocket payloads use a set of aerosol particle, plasma, and optical instruments to study the properties of aerosol particles and their interaction with the ambient plasma environment in the polar mesopause region. In August 2007 the ECOMA-3 payload was launched into a region with Polar Mesosphere Summer Echoes (PMSE) and noctilucent clouds (NLC). An electron depletion was detected in a broad region between 83 and $88 \mathrm{~km}$, coincident with enhanced density of negatively charged aerosol particles. We also find evidence for positive ion depletion in the same region. Charge neutrality requires that a population of positively charged particles smaller than $2 \mathrm{~nm}$ and with a density of at least $2 \times 10^{8} \mathrm{~m}^{-3}$ must also have been present in the layer, undetected by the instruments. A numerical model for the charging of aerosol particles and their interaction with the ambient plasma is used to analyse the results, showing that high aerosol particle densities are required in order to explain the observed ion density depletion. The model also shows that a very high photoionisation rate is required for the particles smaller than $2 \mathrm{~nm}$ to become positively charged, indicating that these may have a lower work function than pure water ice.
\end{abstract}

Keywords. Atmospheric composition and structure (Aerosols and particles; Ion chemistry of the atmosphere; Middle atmosphere - composition and chemistry)

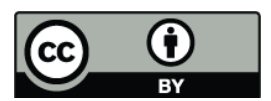

Correspondence to: A. Brattli

(alvin.brattli@ffi.no)

\section{Introduction}

The Earth is continuously bombarded with sub-millimetre meteors at an average global flux estimated between 10 and 100 tons/day (Love and Brownlee, 1993; Gabrielli et al., 2004). The smaller meteors ablate in the mesosphere and create "smoke" particles (Hunten et al., 1980) with a radius of some nanometres through re-condensation and coagulation. These particles are believed to be essential for many middle atmosphere processes. In particular, the formation of ice particles in the middle atmosphere, which form noctilucent clouds (NLC) and cause polar mesosphere summer echoes (PMSE), requires condensation nuclei to be present on which water ice may form, because the water vapour pressure is too small to allow homogeneous nucleation. Smoke particles of meteoric origin are believed to be the most likely condensation nuclei. Additionally, ablation of meteors provides the source material for metal layers that sporadically form in the D-region of the ionosphere (Plane, 1991; McNeil et al., 1998).

A consequence of the presence of aerosol particles in the mesopause region is that one can often observe depletions or "bite-outs" in the electron density. This is because the aerosol particles act as "electron scavengers" - electrons collide with and adhere to aerosol particles. The aerosol particles also scavenge ions, but to a much smaller degree due to the much smaller thermal speed of the ions compared to the electrons. The net result is that the aerosol particles become (on average) negatively charged; more electrons than ions get stuck on the aerosol particles, causing an electron depletion, or (if the aerosol density is high enough) a "bite-out," where practically all electrons adhere to the aerosol particles.

Published by Copernicus Publications on behalf of the European Geosciences Union. 


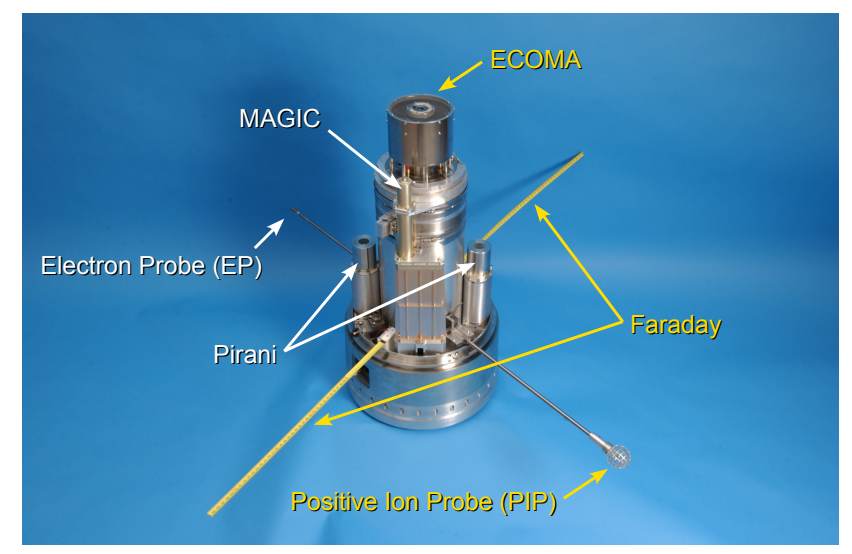

Fig. 1. Top deck (front) of the ECOMA payloads. The instruments used in this analysis have yellow labels. The ECOMA instrument measures charged aerosol particles ( $>2 \mathrm{~nm}$ ), the PIP (Positive Ion Probe) measures positive ion density, while the Faraday instrument measures absolute electron density by Faraday rotation.

The ECOMA project (Existence and Charge state Of Meteoric smoke particles in the middle Atmosphere) aims to measure in-situ the number densities of both charged and uncharged aerosol particles in the mesosphere and lower thermosphere. The data analysed in this paper are from the ECOMA summer campaign in 2007, when a rocket payload was launched into conditions with NLC and PMSE in order to examine the number density and charge state of the aerosol particles.

A companion paper (Rapp et al., 2009) provides an overview of the ECOMA project as well as a detailed presentation of the aerosol particle measurements. Here we shall focus on the electron and ion density measurements. By having a full set of complementary instruments measuring densities of electrons, ions, and charged aerosol particles separately, the payload is designed to keep track of all charge carriers. In addition, we employ a numerical model for the interaction between aerosol particles and the ambient plasma to interpret the measurements.

\section{Experimental results}

\subsection{The rocket payload}

The ECOMA payloads carry a set of instruments to measure and collect samples of charged and uncharged species of aerosol particles in the MLT (Mesosphere/Lower Thermosphere) region, as well as instruments to measure plasma and neutral gas densities. The instruments included in the 2007 campaign were: The ECOMA instrument, whose DC channel measured the net aerosol charge density for particles $>2 \mathrm{~nm}$; a positively biased $(+2.5 \mathrm{~V}$ relative to the payload) electron probe $(\mathrm{EP})$; a negatively biased $(-2.5 \mathrm{~V}$ relative to the payload) positive ion probe (PIP) surrounded by a grid at payload potential; a combined sensor for neutrals and electrons (CONE) for measuring densities of neutrals and electrons; a swept Langmuir probe (Cold Plasma Probe; CPP) for determining the payload potential; two Pirani gauges, to roughly determine neutral density; an instrument for measuring electron density using Faraday rotation and differential absorption (Faraday); a particle sampler collecting aerosol and meteoritic smoke particles (MAGIC); and a photometer for measuring backscattered light from noctilucent cloud (NLC) particles. For a more detailed description of the instruments, see Rapp et al. (2009).

Figure 1 shows the instrument configuration at the front of the payload. The photometer is located in a section below the front deck, and the CPP and CONE instruments are located in the aft of the payload, becoming exposed to the ambient plasma after payload separation. In this analysis, we will use results from the ECOMA, PIP, and Faraday instruments, and the neutral gas temperature derived from the density profile from the CONE instrument is used to convert the PIP current to ion density. Data from the EP is not used in this analysis, since the instrument had too low sensitivity to make usable measurements in the region of interest.

The $2 \mathrm{~nm}$ detection threshold of the ECOMA instrument is caused by aerodynamic effects; simulations show that particles smaller than $2-3 \mathrm{~nm}$ follow the neutral gas flow and are not detected by the instrument (Horányi et al., 1999). If the aerosol particles consist of ice, these simulations show that they will evaporate partially (or completely if they are small) as they enter the compressed region behind the shock front. This, combined with the lower mass density of ice particles, implies that the rejection radius may be larger than $2 \mathrm{~nm}$ for ice particles. In the following we shall for simplicity refer to this as the $2 \mathrm{~nm}$ detection limit, although it should be kept in mind that $2 \mathrm{~nm}$ is a lower bound only.

\subsection{Measurements}

The ECOMA-3 payload was launched from Andøya Rocket Range $\left(69^{\circ} 17^{\prime} \mathrm{N}, 16^{\circ} 01^{\prime} \mathrm{E}\right)$ on 3 August 2007 at 23:22:00 UT. The payload was launched into conditions with PMSE (measured by the $50 \mathrm{MHz}$ ALWIN radar and EISCAT VHF) and NLC (measured by lidar), and reached an apogee of $126.7 \mathrm{~km}$.

Figure 2 shows an overview of the measurements used in this analysis. Two PMSE layers were detected by the radar, at $82-84 \mathrm{~km}$ and at $86-88 \mathrm{~km}$. The PMSE started as a single layer, but split up and weakened before the ECOMA-3 payload was launched. The photometer detected NLC between 82.8 and $87.2 \mathrm{~km}$ on upleg, and between 84.7 and $86 \mathrm{~km}$ on downleg (Megner et al., 2009). Additionally, NLC were detected between 81 and $84 \mathrm{~km}$ by the Alomar RMR Lidar (Baumgarten et al., 2009). The distance between the lidar measurement volume and the rocket trajectory (upleg) was $2 \mathrm{~km}$ at NLC heights. Unfortunately, lidar measurements 


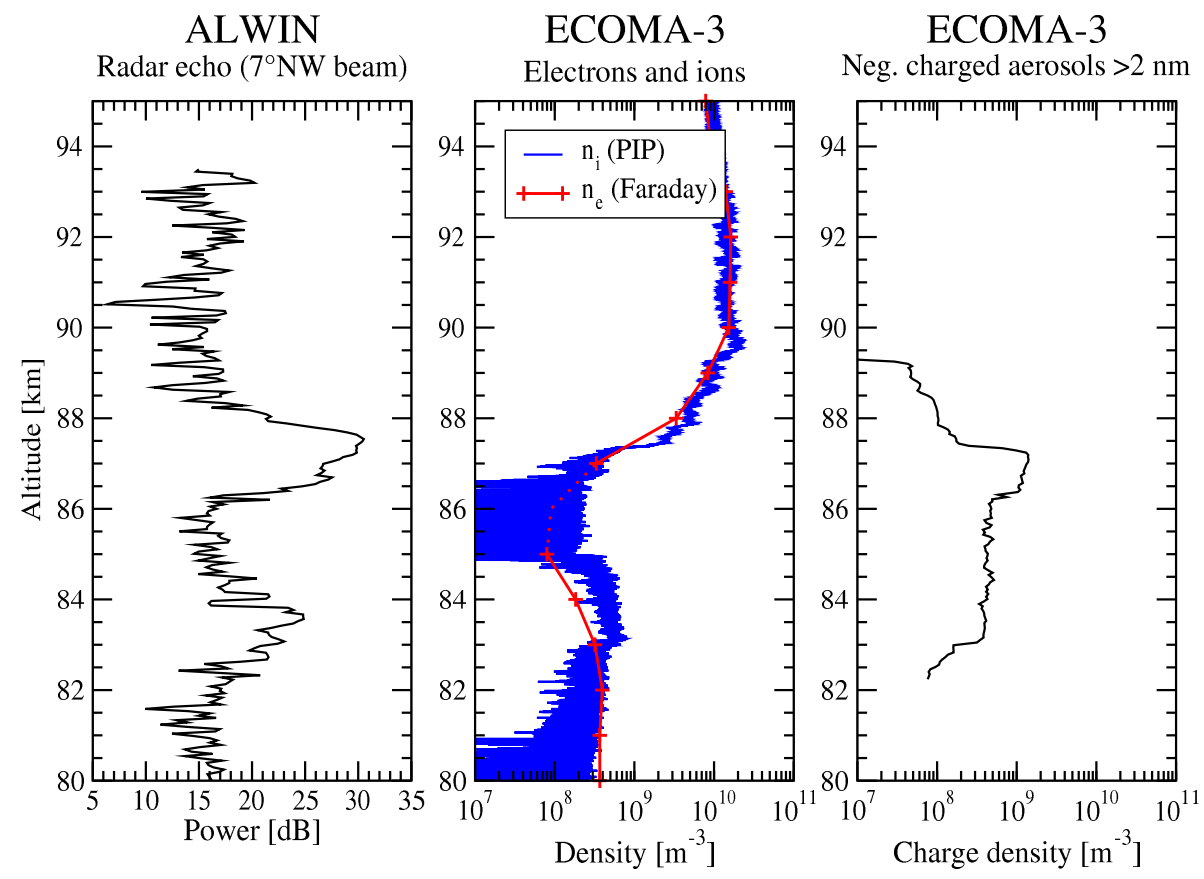

Fig. 2. Left panel: Radar echo, as measured by the ALWIN radar $(50 \mathrm{MHz})$ at the time of launch. The rocket was launched during conditions with PMSE and NLC. Middle panel: Measured electron and ion densities. Between 85 and $87 \mathrm{~km}$ the electron density is below the detection limit of the Faraday instrument, approximately indicated by the dotted, red curve. Right panel: Net negative charge density carried by aerosol particles $>2 \mathrm{~nm}$.

were made impossible from 14 min before launch due to tropospheric clouds.

The middle panel shows the electron and ion densities for the upleg part of the flight, as measured by the Faraday and PIP instruments. The ion density measured by PIP is normalised to the electron density at $92 \mathrm{~km}$, assuming $n_{e}=n_{i}$ at this altitude and above. The electron density is reduced between about 83 and $87 \mathrm{~km}$, and increases sharply with altitude around $88 \mathrm{~km}$. Between about 85 and $87 \mathrm{~km}$, both the phase change and differential absorption measured by the Faraday instrument are below the detection limit. Hence the electron biteout may have been much deeper than the $\sim 1 \times 10^{8} \mathrm{~m}^{-3}$ upper limit indicated in the panel. This is supported by observations from the MASS rocket flown $30 \mathrm{~min}$ before ECOMA-3 (Robertson et al., 2009): it flew through a similar structure, and the electric field measurements of that flight cannot be explained without a much deeper electron biteout (Robertson, private communication). The positive ion density sharply drops below the instrument noise level at $85 \mathrm{~km}$, and stays below the noise level up to about $87.5 \mathrm{~km}$, above which it rises sharply together with the electron density.

The right panel of Fig. 2 shows the charge density (in units of the elementary charge $e$ ) carried by aerosols larger than $2 \mathrm{~nm}$, as measured by the DC channel of the ECOMA instrument. The net aerosol charge was negative. The instrument measured a broad layer, extending approximately from 83 to $87.5 \mathrm{~km}$, of increased aerosol particle density, consistent with both the radar measurements of PMSE and with the decreased electron density in the same region.

The middle panel of Fig. 2 shows that the PIP measurement was quite noisy below $87 \mathrm{~km}$. Before launch, the PIP electrometer measured electronic noise with an amplitude of approximately $0.1 \mathrm{nA}$, as seen in the left panel of Fig. 3. We see the same noise during flight, while the nose cone is on, just a few seconds before the nosecone was jettisoned and the instruments in the front of the payload were exposed to the plasma (second panel from the left). In the altitude region with ion biteout, PIP measured noise only, with the same $0.1 \mathrm{nA}$ noise fluctuations around a mean value of zero (third panel). At $\sim 86 \mathrm{~km}, 0.1 \mathrm{nA}$ corresponds to a positive ion density of $2 \times 10^{8} \mathrm{~m}^{-3}$, effectively making this the lowest ion density we can detect. On downleg, during reentry, we again measured the same amount of electronics noise (rightmost panel). Thus we conclude that $\sim 0.1 \mathrm{nA}$ is the lowest current from PIP that represents a measurable positive ion density, and we call this our noise floor.

The decrease in electron density is coincident with the increased aerosol particle density shown between 83 and $88 \mathrm{~km}$ in Fig. 2. Such an electron depletion is commonly observed in PMSE layers, being caused by free electrons attaching to the aerosol particles. The slightly enhanced positive ion 


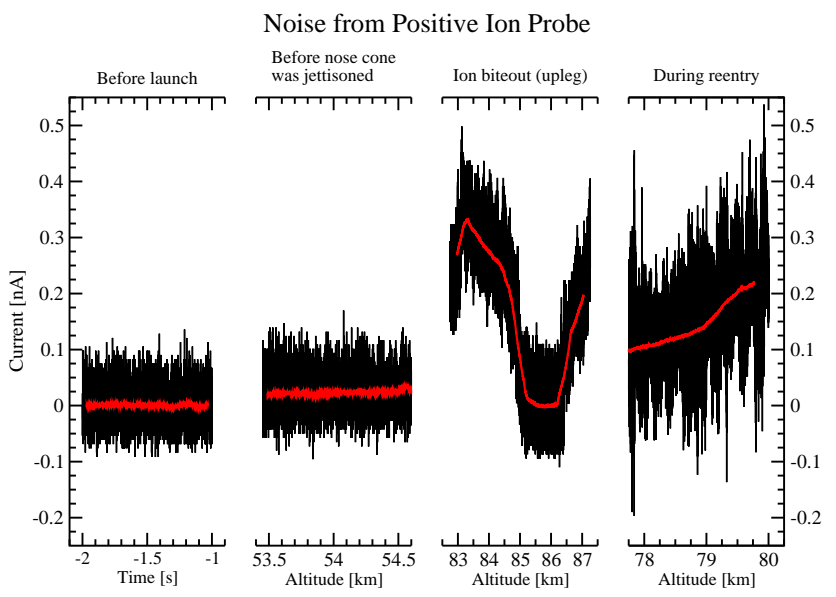

Fig. 3. The current measured by the PIP at different times before and during the flight. The red line is a running mean over $\sim 1$ spin period.

density between 83 and $85 \mathrm{~km}$ is also expected in a region with aerosol particles. Attachment of electrons on aerosol particles leads to a reduction in the electron-ion recombination rate and hence an increase in the ion density. The reduced electron density would lead to an increase in the payload potential relative to the plasma, and therefore a reduced ion current to PIP. Since PIP actually measured an increase in the ion current at $83 \mathrm{~km}$, this increase must have been due to an actual increase in the ion density, and not due to a change in the payload potential.

What is unexpected, however, is the decrease in positive ion density seen by the PIP between 85 and $87 \mathrm{~km}$. Unfortunately, the low sensitivity (high noise level) of the probe, which is clearly visible in Fig. 2, implies that we do not know how strong the reduction is, only that there is a fairly pronounced reduction by at least a factor two in the ion density at approximately $85 \mathrm{~km}$, dipping below the noise level, and an even larger increase in density as the rocket passed $87.5 \mathrm{~km}$

We do not know whether the electrons displayed similarly sharp density gradients; the Faraday measurement has a resolution of about $1 \mathrm{~km}$, essentially limited by the rocket spin period, and the EP instrument (which did have high time resolution) did not make any useful measurements in the region of interest. The sharp increase in ion density at $87.5 \mathrm{~km}$ agrees well with the top of the aerosol particle layer as seen by the ECOMA instrument. However, at the bottom of the ion density depletion, at $85 \mathrm{~km}$, no significant change in the aerosol charge density is seen.

We note from Fig. 2 that at, e.g., $86 \mathrm{~km}$, in the middle of the plasma depletion region, the total negative charge density measured by the ECOMA and Faraday instruments is $4-5 \times 10^{8} e \mathrm{~m}^{-3}$, while the positive density measured by PIP is not more than $2 \times 10^{8} e \mathrm{~m}^{-3}$. Requiring that the plasma must be quasi neutral, a positive charge density of at least $2 \times 10^{8} e \mathrm{~m}^{-3}$ is then "missing". This implies either that at least one of these measurements is not correct, or that most of the positive charge carriers went undetected by all the instruments. In the latter case these must have been (net) positively charged particles smaller than $2 \mathrm{~nm}$ (the detection threshold of the ECOMA instrument). At the same time, these positively charged particles cannot be too small, as they would otherwise be detected by the PIP. For heavy particles the cross section for being collected is close to the geometric cross section of the inner PIP collector, which has a radius of $3.8 \mathrm{~mm}$. For light ions the collection cross section is close to the cross section of the outer grid, which has a radius of $20 \mathrm{~mm}$. Hence the density of heavy, positively charged particles must be about 30 times the positive ion density in order for these two species to contribute equally to the PIP measurement. A similar result is obtained if the payload charging as measured with the CPP instrument, about $-2 \mathrm{~V}$ relative to the plasma at $85 \mathrm{~km}$, is taken into account. With the chosen collector voltage, the cross section becomes small for particles heavier than about 100-200 $m_{u}\left(m_{u}\right.$ is the atomic mass constant; AMU). Unless more than $90 \%$ of the positive charge is carried by heavier particles, the measured PIP current therefore represents particles lighter than roughly $200 m_{u}$. Hence the undetected particles, that are needed to ensure charge neutrality, must be positively charged "smoke" particles smaller than the threshold of $2 \mathrm{~nm}$ for the ECOMA instrument (assuming spherical ice particles with a mass density of $900 \mathrm{~kg} \mathrm{~m}^{-3}, 2 \mathrm{~nm}$ corresponds to a mass of $2 \times 10^{4} \mathrm{~m}_{u}$ ) and heavier than the PIP "threshold" of 100-200 $m_{u}$. If the smoke particles consist mainly of ice which may (partially) evaporate in the shock region around the probe, this former threshold may be higher. Henceforth, we will refer to particles $<2 \mathrm{~nm}$ as "smoke" particles, although we make no distinction or assumptions regarding their origin or chemical composition.

It could be argued that high-velocity collisions between the PIP and ice particles could produce spurious negative charges that could reduce the measured ion current, but we find this unlikely. Since the inner electrode of the PIP is at $-4.5 \mathrm{~V}$ relative to the surrounding plasma (the outer PIP grid is at $-2 \mathrm{~V}$, and the potential difference between the outer grid and the inner electrode is $-2.5 \mathrm{~V}$ ), negatively charged particles such as electrons and negative ions would be rejected by the negative potential of the probe; such particles would have to be quite heavy to cross this potential barrier. Furthermore, for heavy negatively charged particles the contribution to a current to the inner electrode would be limited by the (small) cross-section of the inner electrode. Additionally, the probability that a relatively heavy negatively charged particle would hit the inner probe in a high-velocity collision and deposit an electron on a negatively charged surface is very small. We therefore dismiss this scenario as highly unlikely. 


\section{Numerical modelling}

\subsection{The model}

The numerical model (see Lie-Svendsen et al., 2003) solves the coupled, time-dependent fluid continuity and momentum equations for an arbitrary number of ions and (neutral and charged) aerosol particles, in addition to electrons, in one spatial dimension. Collisions are assumed to be sufficiently frequent to keep all species at the neutral air temperature $T$, which is measured with the CONE instrument. Hence we do not solve the energy equation.

For a species $s$ the continuity equation reads

$\frac{\partial n_{s}}{\partial t}+\frac{\partial\left(n_{s} u_{s}\right)}{\partial z}=Q_{s}-L_{s}$,

where $t$ and $z$ denote time and altitude, respectively, $n_{s}$ and $u_{s}$ are the density and vertical flow speed, and $Q_{s}$ and $L_{s}$ contain the rates for production and loss of particles.

For the light, positive ions, denoted by subscript $i$, the loss rate is

$L_{i}=n_{i}\left(\alpha(z) n_{e}+\sum_{a, Z} \psi_{i, Z} n_{a, Z}\right)$,

where $\psi_{i, Z}$ is the rate coefficient for attachment of positive ions by aerosol particles (subscript $a$ ) and $Z$ denotes the aerosol particle charge. Hence the last term is the loss rate of positive ions caused by attachment by all aerosol species $a$ and charge states $Z$. As will be explained below, we shall consider at most two species $a$, which are only distinguished by different radius and mass, while we include the number of charge states that are necessary (large particles may contain several negative charges). In the first models presented, only one aerosol species is assumed and the sum in Eq. (2) reduces to a sum over charge states $Z$ only.

We include only one species of positive ions, with density $n_{i}$. The electron-ion recombination rate coefficient $\alpha$ is strongly dependent on the kind of positive ion. We therefore consider two cases. In the first case we assume that the positive ion composition changes in the 80$90 \mathrm{~km}$ altitude region. Below $82 \mathrm{~km}$ we choose a constant $\alpha=7 \times 10^{-12} \mathrm{~m}^{3} \mathrm{~s}^{-1}$ (Rapp and Lübken, 2001), corresponding to $\left(\mathrm{H}_{3} \mathrm{O}\right)^{+}\left(\mathrm{H}_{2} \mathrm{O}\right)_{3}$ water cluster ions; between 82 and $88 \mathrm{~km} \alpha$ decreases linearly with altitude, and above $88 \mathrm{~km}$ it is constant at $\alpha=\alpha_{m} \equiv 6 \times 10^{-13} \mathrm{~m}^{3} \mathrm{~s}^{-1}$, corresponding to $\mathrm{NO}^{+}$ions. In the following this altitude dependent $\alpha$ is denoted $\alpha_{c}$. In the second case we use the $\mathrm{NO}^{+}$value $\alpha_{m}$ everywhere. The density $n_{i}$ thus represents the total (cluster plus molecular) ion density. The production rate for light ions (and electrons), $Q_{i}(z)$, is chosen such that the observed electron (and ion) density in the absence of aerosol particles, $n_{0}(z)$, is reproduced in the steady state, whence

$Q_{i}(z)=\alpha n_{0}^{2}$.
For aerosol particles of charge $Z$ (in units of $e$ ) the source and loss rates are written

$Q_{a, Z}=\psi_{e, Z+1} n_{e} n_{a, Z+1}+\psi_{i, Z-1} n_{i} n_{a, Z-1}+I_{a} n_{a, Z-1}$

$L_{a, Z}=n_{a, Z}\left(\psi_{e, Z} n_{e}+\psi_{i, Z} n_{i}\right)+I_{a} n_{a, Z}$

where $I_{a}$ is the photoionisation rate.

We use the rate coefficients for attachment of electrons and positive ions by aerosol particles derived by Natanson (1960) (and reviewed by Rapp (2000)), except that for attractive interactions we have included the induced dipole force as newly derived by Robertson and Sternovsky (2008). For electrons the attachment rates are

$$
\begin{aligned}
\psi_{e, 0}= & \pi r_{a}^{2} c_{e}\left(1+\sqrt{\frac{e^{2}}{8 \epsilon_{0} k T r_{a}}}\right) \\
\psi_{e, Z>0}= & \pi r_{a}^{2} c_{e}\left(1+C_{Z} \sqrt{\frac{e^{2}}{16 \epsilon_{0} k T r_{a}}}+D_{Z} \frac{|Z| e^{2}}{4 \pi \epsilon_{0} k T r_{a}}\right) \\
\psi_{e, Z<0}= & \pi r_{a}^{2} \gamma^{2} c_{e} \\
& \exp \left[-\frac{|Z| e^{2}}{4 \pi \epsilon_{0} k T r_{a} \gamma}\left(1-\frac{1}{2 \gamma\left(\gamma^{2}-1\right)|Z|}\right)\right],
\end{aligned}
$$

where $k$ is Boltzmann's constant; $\epsilon_{0}$ the permittivity of vacuum (SI units are used throughout); $r_{a}$ the aerosol particle radius; $c_{e} \equiv \sqrt{8 k T /\left(\pi m_{e}\right)}$ is the mean thermal electron speed; $\gamma$ is given by Natanson (1960), ranging from 1.62 for $|Z|=1$ to 1.22 for $|Z|=7$; and $C_{Z}$ and $D_{Z}$ are given in Table 1 of Robertson and Sternovsky (2008). The inclusion of the induced dipole force in the attractive case increases the attachment rate by approximately a factor 2 for small $r_{a}$ and $Z=1$, compared with the original Natanson expression (which only accounts for the Coulomb force). The corresponding positive ion attachment rates $\psi_{i, 0}, \psi_{i, Z>0}$, and $\psi_{i, Z<0}$ are obtained from Eqs. (6), (8), and (7), respectively, replacing $c_{e}$ with $c_{i} \equiv \sqrt{8 k T /\left(\pi m_{i}\right)}$. We use the $\mathrm{NO}^{+}$mass $m_{i}=30 m_{u}$ in all cases. Since the attachment rates are proportional to $m_{i}^{-1 / 2}$, this leads to a modest error in the rate coefficients for the cluster ions in the lower part of the computational domain for the cases with an altitude-dependent $\alpha=\alpha_{c}$. The electron density is given by the charge neutrality requirement, and hence we do not need explicit expressions for the electron production and loss rates.

We do not include production and loss of aerosol particles by ice particle condensation, coagulation or evaporation. Hence the total number of aerosol particles will be conserved during the time integration of the model; only the charge and altitude distribution will change.

Turning to the momentum equation for each species, we only consider time scales at which inertial effects (acceleration) may be neglected, in which case the momentum (equals force balance) equation may be written

$n_{0}$ is specified below. 
Table 1. Summary of model parameters used in the figures, where $r_{a}$ is the aerosol particle radius and $\alpha$ is the electron-ion recombination rate coefficient.

\begin{tabular}{ccrc}
\hline Figure no. & Smoke particles? & $r_{a}[\mathrm{~nm}]$ & $\alpha$ \\
\hline 4 & No & 2 & $\alpha_{m}$ \\
5 & No & 50 & $\alpha_{c}$ \\
6 & Yes & 50 & $\alpha_{c}$ \\
7 & Yes & 10 & $\alpha_{m}$ \\
8 & Yes & 50 & $\alpha_{m}$ \\
\hline
\end{tabular}

$$
\begin{aligned}
\frac{\partial P_{s}}{\partial z} & +n_{s} m_{s} g-n_{s} Z_{s} e E= \\
& -n_{s} m_{s} v_{s} u_{s}+m_{s} \sum_{t}\left(n_{t} u_{t} R_{t s}-n_{s} u_{s} R_{s t}\right) .
\end{aligned}
$$

Here $P_{s}=n_{s} k T$ is the pressure of species $s ; m_{s} g$ is the gravitational force; $Z_{s} e$ the particle charge and $E$ is the electric field; and $v_{s}$ is the momentum transfer collision frequency for collisions with the neutral atmosphere. We neglect updraft of the neutral atmosphere. The collision frequencies are obtained from Hill and Bowhill (1977) for positive ions and from Schunk (1977) for aerosol particles (assuming hardsphere interactions), using the measured neutral air density (and derived temperature) from the CONE instrument. The last term in Eq. (9) contains the aerosol particle momentum transfer caused by ionisation and attachment of ions and electrons, where the sum extends over the "adjoining" charge states $Z_{s} \pm 1$, and $R_{s t}$ is the rate of transfer from species $s$ to $t$.

We require a quasi-neutral plasma with no currents. Hence

$n_{e}=\sum_{s} Z_{s} n_{s}$

$u_{e}=\frac{1}{n_{e}} \sum_{s} Z_{s} n_{s} u_{s}$

where the sums are over all species, except electrons. The electric field is then obtained from the electron momentum equation, and to a very good approximation

$E=-\frac{k T}{e} \frac{1}{n_{e}} \frac{\partial n_{e}}{\partial z}$.

We use data from the DC channel of the ECOMA particle instrument as aerosol particle density input to the model. In this study we are not concerned with the small-scale density variations. We therefore use the ECOMA data with the resolution reduced to approximately $50 \mathrm{~m}$. At these scales ambipolar diffusion, for which the electric field is critical, is of little importance. For small particles we could have neglected vertical transport altogether, and just solved the continuity equation without the flux divergence term. For the larger NLC-size particles that we shall also consider, gravity becomes important, and they may fall too fast to reach complete ionisation equilibrium. However, it turns out that the resulting gravitational settling does not have a large impact on particle densities, and assuming ionisation equilibrium is a fairly good approximation even for the heaviest particles we consider. When the model is started far from steady state, the last term in Eq. (9) also contributes significantly to the force balance (although the term has a small impact on the steady state solution).

All model calculations are started with an assumed initial aerosol particle density profile, with all particles being neutral at the start of the calculation. Electrons and ions are initially in ionisation equilibrium with the $\alpha$ and $Q_{i}$ specified above. The model is run until a (quasi-) steady state has been reached, typically in $10^{4} \mathrm{~s}$ or less of model time. The upper and lower boundaries are at 80 and $90 \mathrm{~km}$, sufficiently far away that the structures we focus on are not affected by boundary conditions on this time scale, only by the initial particle density distribution.

We assume an initial electron and ion density $n_{0}(z)$ that equals the Faraday electron density below $82 \mathrm{~km}$ and above $88 \mathrm{~km}$. Between 82 and $88 \mathrm{~km}$ the observed electron density is depleted, which we attribute to the presence of aerosol particles. We therefore assume that, had aerosol particles not been present, the electron and ion density would have increased monotonically in this region. For simplicity we choose $\log \left(n_{0}(z)\right)$ to increase linearly with altitude between 82 and $88 \mathrm{~km}$. With the altitude-dependent recombination rate, $\alpha=\alpha_{c}$, Eq. (3) then leads to an electron-ion production rate $Q_{i} \approx 10^{6} \mathrm{~m}^{-3} \mathrm{~s}^{-1}$ at $80 \mathrm{~km}, 7 \times 10^{6} \mathrm{~m}^{-3} \mathrm{~s}^{-1}$ at $88 \mathrm{~km}$, and then increasing rapidly to $1.4 \times 10^{8}$ at $90 \mathrm{~km}$ in order to reproduce the rapidly increasing plasma density above the particle layer. With the low recombination rate, $\alpha=\alpha_{m}$, the production rate near the lower boundary of the model is reduced by an order of magnitude, to $Q_{i} \approx 8 \times 10^{4} \mathrm{~m}^{-3} \mathrm{~s}^{-1}$ at $80 \mathrm{~km}$. At $t=0$ (when aerosol particles are neutral) we set $n_{e}(z)=n_{i}(z)=n_{0}(z)$.

\subsection{Model results}

Our aim is to identify conditions that can produce the plasma and particle densities seen in Fig. 2, and in particular the positive ion density depletion. Rapp and Lübken (2001) carried out an extensive parameter study of aerosol particle charging effects on the plasma. They found that an ion density depletion can be achieved if the recombination rate $\alpha$ is small (corresponding to molecular ions) or if the aerosol particle number density and radius are both sufficiently large. As our model is very similar to theirs, this conclusion still applies.

The two main model parameters that are to be varied below are the particle size $r_{a}$ and the recombination rate coefficient $\alpha$, as summarized in Table 1. We shall present five different models, shown in Figs. 4-8. In Fig. 4, small $(2 \mathrm{~nm})$ particles and a low $\alpha=\alpha_{m}$ is assumed, while in Fig. 5 large $(50 \mathrm{~nm})$ particles and a high $\alpha=\alpha_{c}$ are assumed. In Figs. 6-8 smoke 
particles are added. In Fig. 6, $50 \mathrm{~nm}$ particles are assumed with a high $\alpha=\alpha_{c}$, while in Fig. $710 \mathrm{~nm}$ particles and a low $\alpha=\alpha_{m}$ are assumed. Finally, in Fig. 8 both large $(50 \mathrm{~nm})$ particles and a low $\alpha=\alpha_{m}$ are assumed.

\subsubsection{Without smoke particles}

As remarked in Sect. 2.2, charge neutrality requires that, if all measurements are correct, an undetected population of light, positively charged smoke particles $<2 \mathrm{~nm}$ must have been present. Before we include smoke particles, we consider the simpler case of just one population of aerosol particles $\geq 2 \mathrm{~nm}$, which would be detected by the ECOMA instrument. Since the model enforces strict charge neutrality, the model in this case obviously cannot reproduce all the charged particle measurements. The goal is to show under which conditions the ion density depletion can be reproduced, without the complexity added by a population of smoke particles.

As indicated above, an ion density depletion can be obtained if the recombination coefficient $\alpha$ is small, or with a large number of large aerosol particles. We first consider the case of a small recombination coefficient, setting $\alpha=\alpha_{m}$. The aerosol particles are assumed to be of a single size, $r_{a}=2 \mathrm{~nm}$, at the detection threshold of the ECOMA DC instrument. Since NLC were observed during the rocket flight, we know that much larger particles must have been present. However, in this first model case we want to show the effect if small particles are the dominant charge carriers. We include the charge states from $Z=-2$ to $Z=1$ in the model, a range sufficient for small particles.

When choosing the aerosol particle number density needed as input to the model, it would be natural to use the actual measurements from the ECOMA instrument shown in Fig. 2, converting the charge density to number density assuming that all particles carry a single negative charge. If we do that, the model calculations show that essentially all particles acquire a single negative charge, as expected (as mentioned, the model calculation starts with all particles being neutral). However, the electron and ion measurements are not reproduced: The electron density is slightly reduced relative to $n_{0}$, but is still almost $10^{9} \mathrm{~m}^{-3}$ in the region where the Faraday instrument measures a complete biteout. Moreover, the ion density is not reduced at all, showing instead a small increase relative to $n_{0}$. In this case, the reduction in the electron-ion recombination rate caused by electron attachment on aerosol particles is as important for the ion density as ion attachment on aerosol particles, and the two effects nearly cancel.

For such small particles to produce a sizeable change in $n_{e}$ and $n_{i}$, a much higher aerosol density is required, and to reproduce the observed reduction in $n_{i}$ the aerosol particle density has to be approximately 100 times the charge density measurement from the ECOMA instrument. Figure 4 shows the resulting densities when the measurement from the DC channel of the ECOMA instrument has been multiplied by a factor 100 everywhere. Although the total particle density is now very large, $10^{10}-10^{11} \mathrm{~m}^{-3}$, most of the particles remain neutral and the density of positively and negatively charged particles are almost equal in the particle layer. Hence the modelled aerosol particle charge density,

$n_{D C} \equiv \sum_{s, r_{s}>2 \mathrm{~nm}} Z_{s} n_{s}$,

which is the quantity measured by the DC channel of the ECOMA instrument, is actually somewhat lower than the measured charge density, despite the very large aerosol particle density assumed. The large particle density leads to a strong electron biteout below approximately $88 \mathrm{~km}$, and almost to the required reduction in ion density between 85 and $87 \mathrm{~km}$, where the ion density depletion was observed.

The model in Fig. 4 includes photoionisation of aerosol particles (given by $I_{a}$ ). Without photoionisation the electron density would be of order $10^{6} \mathrm{~m}^{-3}$ or less inside the whole particle layer while the ion density at e.g. $86 \mathrm{~km}$ increases slightly to $5 \times 10^{8} \mathrm{~m}^{-3}$, which exceeds the PIP measurement (the extremely low electron density leads to reduced electron-ion recombination and hence an increased ion density).

Although the modelled ion density fits the measured ion density in the upper part of the layer $(>85 \mathrm{~km})$, the modelled density is much too low in the bottom part of the layer. Recall, however, that we arbitrarily increased the aerosol particle density by a factor 100 everywhere; the low $n_{i}$ in the lower part of the layer could easily be increased by choosing a smaller aerosol particle density in that region. Also, the calculated $n_{D C}$ is too low compared with observations. As emphasised in Sect. 2.2, a model that requires charge neutrality cannot reproduce all of the measured particle densities without smoke particles; we will need an additional species that has gone undetected by the instruments. However, the main point is that, with a combination of a very high aerosol particle density, of order $10^{11} \mathrm{~m}^{-3}$, and a low electron-ion recombination rate, applicable to $\mathrm{NO}^{+}$ions, small particles may produce the required reduction in the positive ion density.

If we had used the larger value of the recombination coefficient, $\alpha=\alpha_{c}$, in the model of Fig. 4 , but otherwise the same input parameters, we would obtain a higher ion density, close to the unperturbed $n_{0}$. The result that increasing the recombination rate $\alpha$ leads to an increase in the ion density, is counterintuitive. By itself an increase in $\alpha$ causes a decrease in $n_{i}$ since ionisation equilibrium requires a constant $Q_{i}=L_{i}$, and from Eq. (2) an increased $\alpha$ must then be accompanied by a decreased $n_{i}$ (and possibly $n_{e}$ ). However, it is the undisturbed density $n_{0}$ that is kept constant when $\alpha$ is increased, and from Eq. (3) $Q_{i}$ is then increased proportionally to $\alpha$. For small $\alpha$ the second term in Eq. (2) may dominate, while for large $\alpha$ it will become negligible. Whereas the first term in Eq. (2) leads to an increased $n_{i}$ when aerosol particles are present (because $n_{e}$ is reduced by aerosol attachment), the 

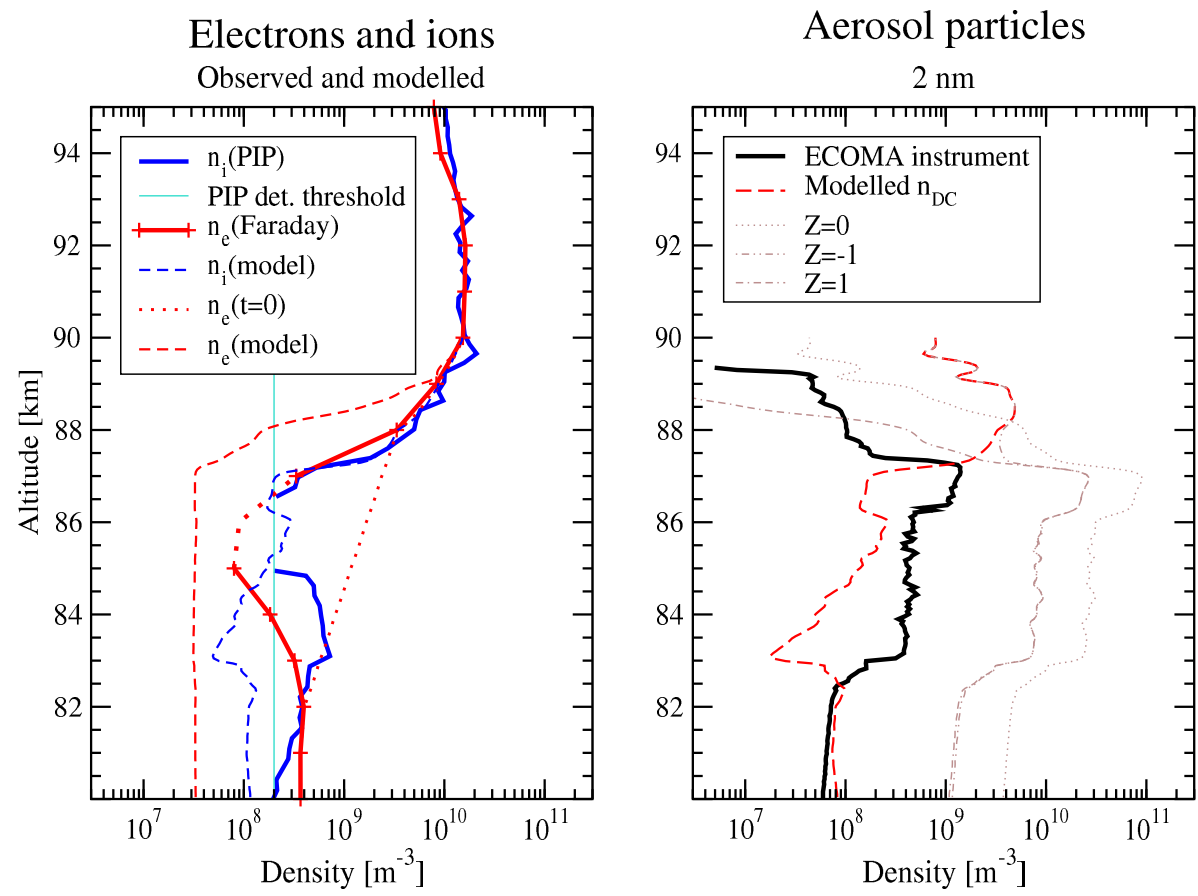

Fig. 4. Modelled and observed electron, ion, and aerosol particle densities. The model assumes $\alpha=\alpha_{m}=6 \times 10^{-13} \mathrm{~m}^{3} \mathrm{~s}^{-1}, n_{0}$ as the initial electron and ion density (thin dotted line), $r_{a}=2 \mathrm{~nm}, I_{a}=10^{-3} \mathrm{~s}^{-1}$, and an aerosol particle density which is 100 times the charge density measurement from the DC channel of the ECOMA instrument (assuming all particles have $Z=-1$ ). $n_{D C}$ is the modelled aerosol particle charge density defined by (13).

second term - ion attachment by aerosol particles - leads to a decrease in $n_{i}$ when the aerosol particle density $n_{a, Z}$ is increased. Hence the relative importance of the two terms in Eq. (2) determines whether the ion density will increase or decrease in response to an increase in aerosol particle density. A sufficiently low recombination rate makes the second term dominant, causing a decrease in ion density.

Since the attachment rate is proportional to $r_{a}^{2}$, it increases rapidly with increasing particle size. The large total surface area of NLC-sized particles implies that a reduction in positive ion density can be achieved with a more modest aerosol particle density than assumed for the calculations using only $2 \mathrm{~nm}$-sized aerosol particles, and without choosing a small value for the recombination rate coefficient $\alpha$. The onboard photometer detected NLC with particle size of order $40 \mathrm{~nm}$ on both up- and downleg (Megner et al., 2009). Both the photometer and the ECOMA instrument detected particles in a broad region between 83 and $88 \mathrm{~km}$.

In the model solution shown in Fig. 5 we illustrate the effect of large particles by assuming a single particle radius of $50 \mathrm{~nm}$ throughout the layer measured by the ECOMA instrument, and the high recombination rate coefficient $\alpha=\alpha_{c}(z)$. The figure shows that the required reduction in $n_{i}$ can be achieved with an aerosol particle density that is "only" 10 times higher than the charge density measurement of the DC channel of the ECOMA instrument - $\max \left(n_{a, Z}\right)=1.4 \times 10^{10} \mathrm{~m}^{-3}$. (The chosen large aerosol particle photoionisation rate $I_{a}=0.3 \mathrm{~s}^{-1}$ prevents a deep electron biteout; reducing instead $I_{a}$ to $10^{-2} \mathrm{~s}^{-1}, n_{e}$ would be less than $10^{7} \mathrm{~m}^{-3}$ in the particle layer, while $n_{i}$ does not change much.) Since this model leads to comparable, and low, electron and ion densities in the particle layer, consistent with the measurements, the charge neutrality enforced by the model implies that the average charge of the aerosol particles (expressed through $n_{D C}$ ) must also be close to zero.

Assuming particles with $20 \mathrm{~nm}$ radius - the approximate lower limit of NLC particles - a result similar to that shown in Fig. 5 is obtained if the aerosol particle density is increased by another factor of $3\left(\max \left(n_{a, Z}\right) \approx 4 \times 10^{10} \mathrm{~m}^{-3}\right)$.

\subsubsection{With smoke particles}

If the model is to satisfy all charged particle measurements, charge neutrality requires a population of small $(<2 \mathrm{~nm})$, positively charged smoke particles to be present. Small, positive NLC particles $>2 \mathrm{~nm}$ would be detected by the ECOMA instrument. Particles $<2 \mathrm{~nm}$ are too small to be considered NLC particles, so we refer to them as "smoke" particles. Since these cannot be detected by the DC channel of the ECOMA instrument, we have no direct, observational constraint on their number density and altitude distribution. We therefore assume an additional population of $r_{a}=1.5 \mathrm{~nm}$ 

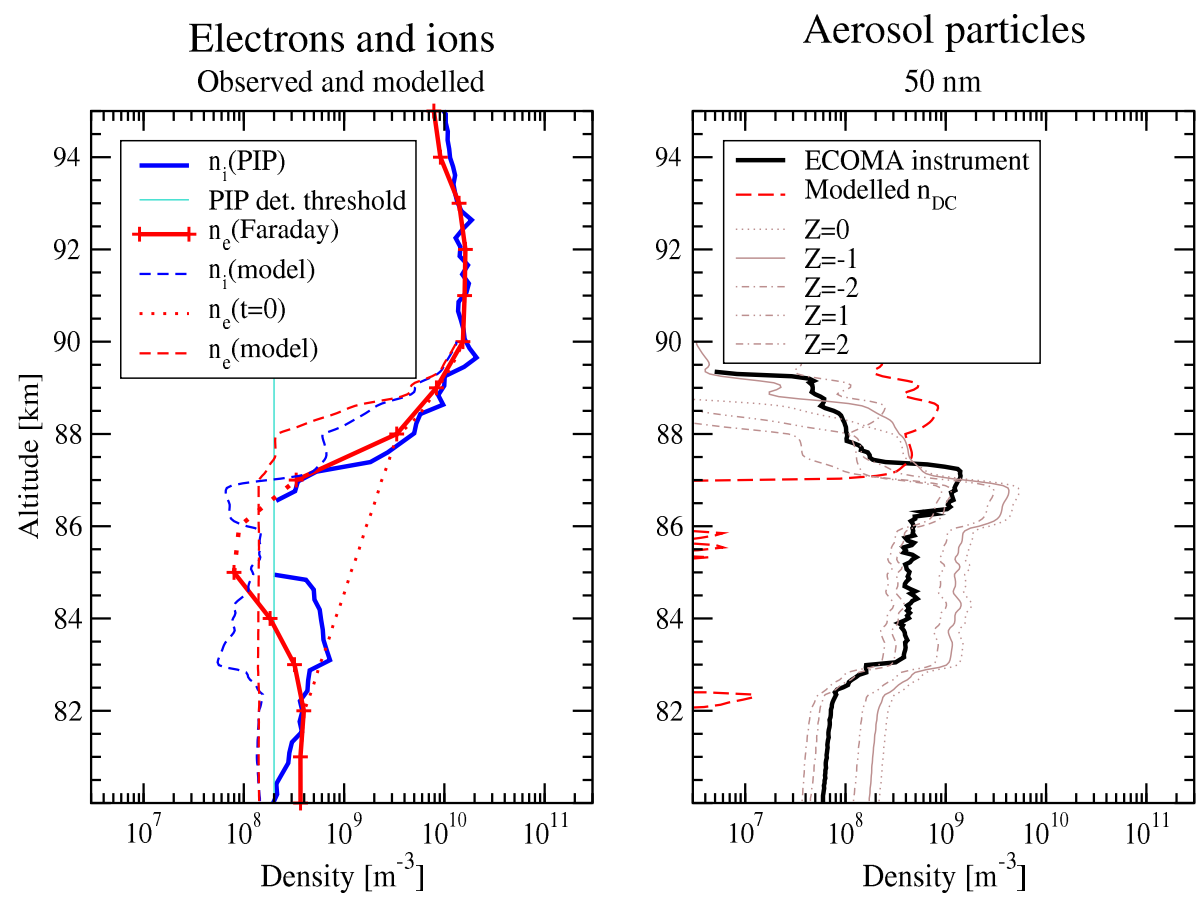

Fig. 5. Model results assuming $\alpha=\alpha_{c}, r_{a}=50 \mathrm{~nm}, I_{a}=0.3 \mathrm{~s}^{-1}$, charge states $Z=-5$ through $Z=3$, and an aerosol particle density which is 10 times the charge density measurement of the ECOMA instrument.

particles, with a Gaussian density distribution with altitude centred at $85 \mathrm{~km}$, inside the aerosol particle layer (as seen by the ECOMA instrument), and with a Gaussian width (defined as where the density is reduced by a factor $\exp (-1)$ from its maximum value) of $4 \mathrm{~km}$. Since large particles or a reduced value for $\alpha$ (and hence lower $Q_{i}$ from Eq. (3)) may both lead to a reduction in $n_{i}$, we consider both scenarios.

In Fig. 6 large $(50 \mathrm{~nm})$ particles and $\alpha=\alpha_{c}(z)$ (representing a varying mixture of cluster and molecular ions) are assumed. The chosen parameters indicate approximately what is required to reproduce all observations: At $\sim 85 \mathrm{~km}$ the positive ion density is reduced below the PIP instrument detection threshold, the electron density is comparable to the Faraday measurement, while the aerosol particle charge density $n_{D C}$ (which, from Eq. (13), only counts particles with $r_{a}>2 \mathrm{~nm}$ ) agrees approximately with what was measured by the ECOMA instrument. Note that in this model, too, the density of NLC particles is very large, $\sim 10^{10} \mathrm{~m}^{-3}$, which is required to produce a sufficiently low $n_{i}$. The density of NLC-sized particles is also much larger than the density of small smoke particles; we need a large number of large particles in order to reduce $n_{i}$, although most of those particles will remain neutral, while we need a smaller number of small particles to contain the "missing" positive charge. A density of order $10^{10} \mathrm{~m}^{-3}$ for such large particles implies an extremely high water mixing ratio. Assuming the particles are solid ice with a density of order $10^{3} \mathrm{~kg} / \mathrm{m}^{3}$, it translates into a mixing ratio of more than $10^{3} \mathrm{ppmv}$, orders of magnitude larger than the water vapour mixing ratio observed in the mesopause region (see Sect. 4).

The same charged particle observations can also be approximately reproduced in a quite different scenario, assuming that the ion depletion occurs in a region dominated by molecular ions, and hence with a much lower electron-ion recombination coefficient. Figure 7 shows that in this case, even $10 \mathrm{~nm}$ particles can produce the required reduction in $n_{i}$ assuming a maximum aerosol particle density of not more than about $10^{10} \mathrm{~m}^{-3}$, the same particle density as in the $50 \mathrm{~nm}$ case of Fig. $6.10 \mathrm{~nm}$ particles with this density implies a water mixing ratio of order $10 \mathrm{ppmv}$.

In both cases shown in Figs. 6 and 7, the smoke particles have only a small impact on electrons and ions, as seen by comparing Figs. 5 and 6. The "role" of the smoke particles in both scenarios is, through the very high photoionisation rate, to release electrons that in turn attach to the larger particles detected by the ECOMA instrument, causing a negative charge density to be measured by ECOMA. Without photoionisation the modelled ECOMA density $n_{D C}$ would become negative, implying that the ECOMA instrument should have measured a positive current.

Finally, the aerosol density required to produce the ion depletion can be further reduced by assuming both large particles and a reduced $\alpha$. Figure 8 shows that with an aerosol particle size of $50 \mathrm{~nm}$ and $\alpha=\alpha_{m}$, an aerosol density 

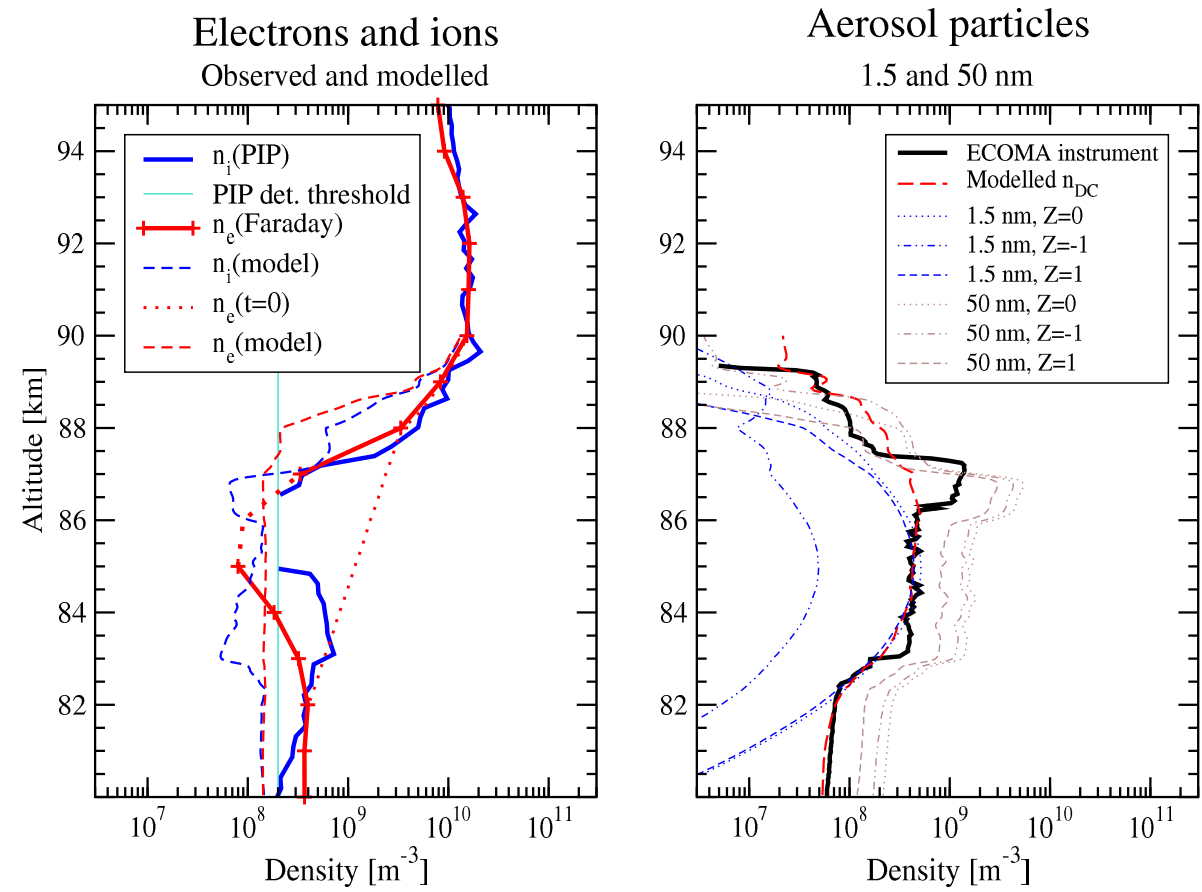

Fig. 6. The same model as in Fig. 5, except that we have added "smoke" particles with $r_{a}=1.5 \mathrm{~nm}$, a Gaussian altitude distribution with a peak density of $10^{9} \mathrm{~m}^{-3}$ at $85 \mathrm{~km}$, and a smoke particle photoionisation rate $I_{a}=10^{-2} \mathrm{~s}^{-1}$.
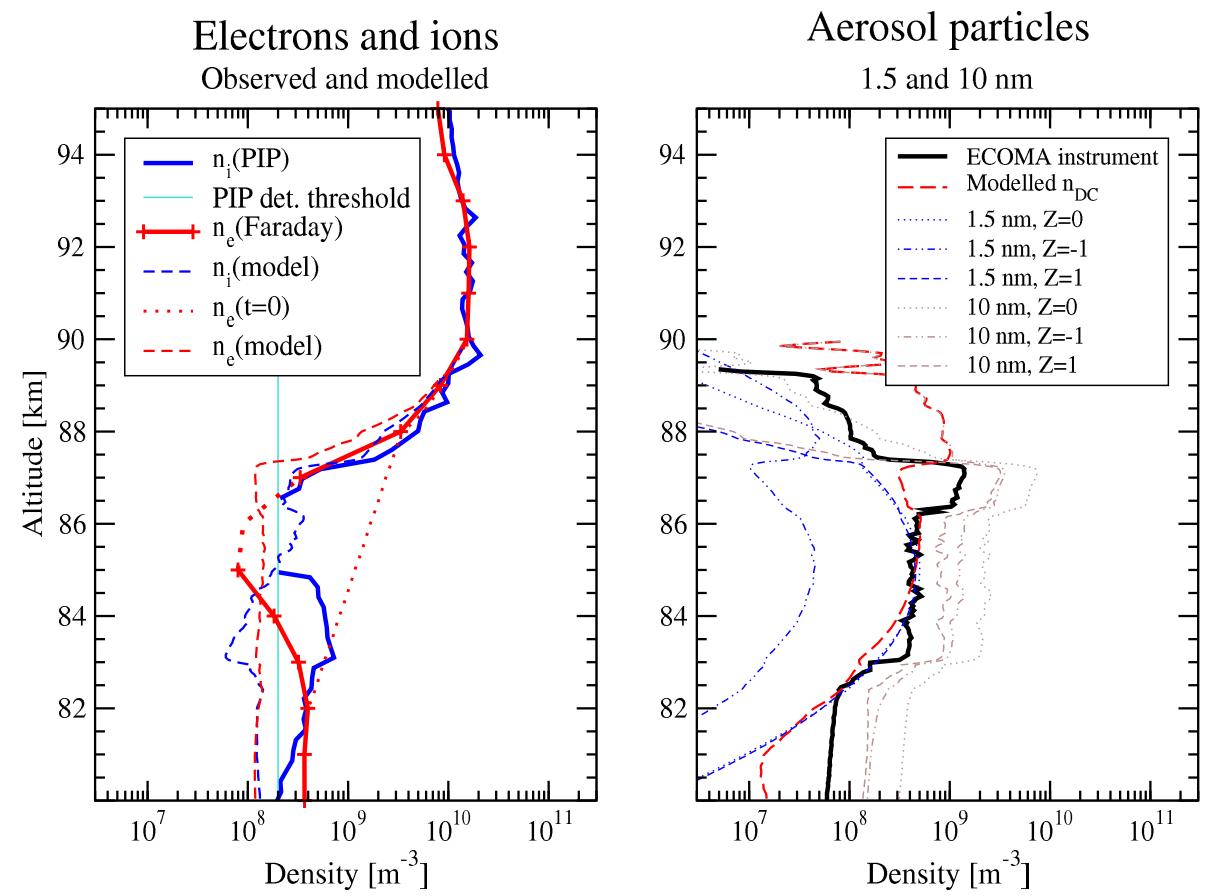

Fig. 7. Model with the same $r_{a}=1.5 \mathrm{~nm}$ smoke distribution as in Fig. 6 , and in addition $r_{a}=10 \mathrm{~nm}$ particles with 10 times the density measured by the ECOMA instrument (assuming all particles have $Z=-1$ ). A recombination coefficient $\alpha=\alpha_{m}$ is used, and $I_{a}=10^{-2} \mathrm{~s}-1$ and $3 \times 10^{-2} \mathrm{~s}^{-1}$ for the 1.5 and $10 \mathrm{~nm}$ particles, respectively. 

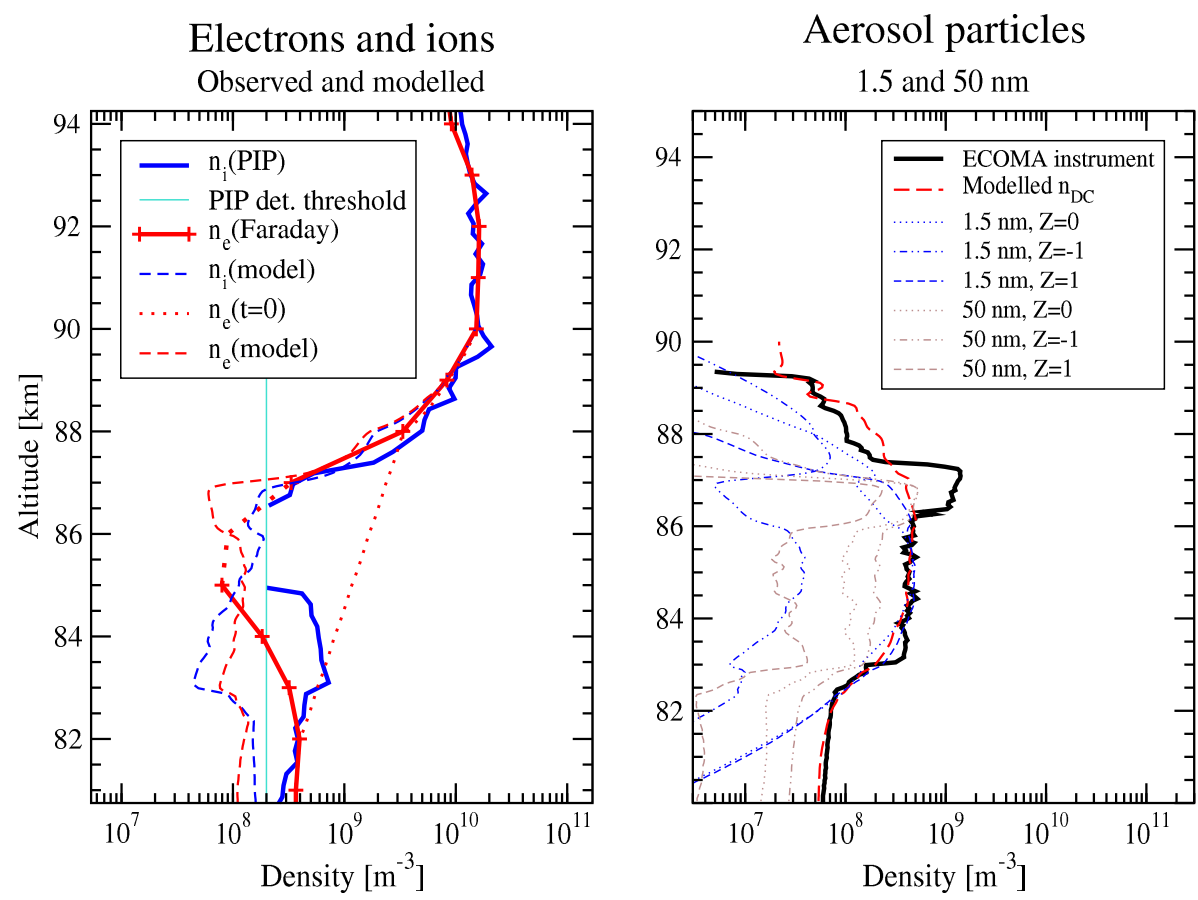

Fig. 8. Model with $\alpha=\alpha_{m}$ and two aerosol particle populations, one with $r_{a}=50 \mathrm{~nm}$ and the same density as measured by the ECOMA instrument (assuming singly negatively charged particles), and a smoke population with $r_{a}=1.5 \mathrm{~nm}$ and the same density as in Fig. 6 . $I_{a}=0.1$ and $0.01 \mathrm{~s}^{-1}$ for the 50 and $1.5 \mathrm{~nm}$ particles, respectively.

of approximately $5 \times 10^{8} \mathrm{~m}^{-3}$ is sufficient to produce the required reduction in $n_{i}$ around $86 \mathrm{~km}$. This size and density corresponds to a water mixing ratio of order 50 ppmv.

Although we initially assumed a particle density for the $50 \mathrm{~nm}$ particles equal to the measurement by the ECOMA instrument, assuming that all particles carried a single negative charge, the solution in Fig. 8 shows that the density of $Z=-1$ particles is significantly lower than this assumed value. A significant number of $Z=-2$ particles compensates for this, so that $n_{D C}$ is still in approximate agreement with the measurement made by the ECOMA instrument.

\section{Discussion}

A reduction in positive ion density inside a PMSE/NLC layer is quite unusual; in fact, we are aware of only three published measurements (Pedersen et al., 1970; Balsiger et al., 1996; Blix, 1999). A rocket launched from Andøya in June 1966 detected a depletion in both electron and ion densities in a thin layer in the mesopause region (Pedersen et al., 1970). The ion depletion was attributed to a wake effect, although they also detected a notable decrease in the positive ion current from the front grid, which is difficult to attribute to a wake effect. The MASS rocket also detected a reduction in positive ion density between 86 and $88 \mathrm{~km}$, indicating that it may have flown through the same layer as the ECOMA-3 rocket (Robertson et al., 2009).

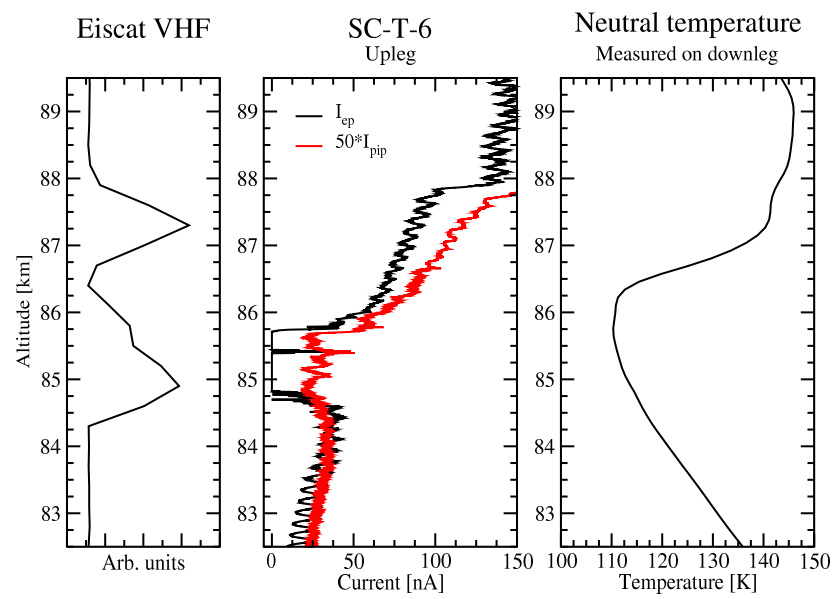

Fig. 9. Electron biteout measured during the SCALE campaign in 1993 (Blix, 1999). The left panel shows PMSE as measured by the EISCAT VHF $(224 \mathrm{MHz})$ radar. The middle panel shows the currents to the electron probe, $I_{\mathrm{EP}}$, and the positive ion probe, $I_{\mathrm{PIP}}$ ( $I_{\mathrm{PIP}}$ has been scaled with a factor of 50 for presentation purposes). The right panel shows the neutral temperature, as measured by the CONE instrument on downleg.

In Fig. 9 we show the ion density depletion detected in 1993 as part of the SCALE (SCAttering Layer Experiment) campaign (Blix, 1999). The payload was launched on 1 
August 1993 at 01:46:00 UT during conditions with PMSE, as measured by the EISCAT VHF radar $(224 \mathrm{MHz}) 125 \mathrm{~km}$ from the rocket trajectory. A photometer on board the payload also measured NLC in the same altitude range (approximately $84.5-85.5 \mathrm{~km}$ ) as the on-board plasma probes detected an electron biteout and a reduction in ion density. The left panel of Fig. 9 shows the PMSE, as measured by the $224 \mathrm{MHz}$ EISCAT VHF radar. The middle panel shows the measurements from the outer grid of the CONE instrument, measuring electron density, and from the PIP instrument in the front of the payload. Between 84.5 and $86 \mathrm{~km}$ there is a deep electron biteout, with no measurable amount of electrons for $\approx 1 \mathrm{~km}$, except for a very thin layer $(\sim 100 \mathrm{~m})$ at $85.4 \mathrm{~km}$. Colocated with the electron biteout there is a reduction in the positive ion density. The right panel of Fig. 9 shows the neutral gas temperature, as measured by the CONE instrument on downleg. The mesopause, with its temperature minimum of $110 \mathrm{~K}$, is at roughly $85 \mathrm{~km}$. The location of the temperature minimum fits well with NLC being observed at these altitudes.

Given that most rocket payloads do not carry both electron and ion current probes, ion density depletions in mesopause particle layers may actually be more common than these few observations indicate.

This is also supported by Havnes et al. (2007). Modelling the PMSE overshoot effect (Havnes et al., 2003; Havnes, 2004), they get both electron and ion depletions when using ground-based, high-power HF transmitters to artificially heat the electrons in aerosol layers containing PMSE-sized particles.

Although models with $\alpha=\alpha_{c}$ are able to reproduce the measurements of the ECOMA instrument, and particularly the reduction in $n_{i}$, assuming large particles, the aerosol particle density has to be very high, of order $10^{10} \mathrm{~m}^{-3}$ (Fig. 6), implying a water mixing ratio of more than $10^{3} \mathrm{ppmv}$ for $50 \mathrm{~nm}$ particles. Observations indicate water vapour mixing ratios in the mesopause region of order 1-2 ppmv (e.g. Bevilacqua et al., 1983; Seele and Hartogh, 1999). Conversely, for $50 \mathrm{~nm}$ particles, $1 \mathrm{ppmv}$ translates into an ice particle density of only about $10^{7} \mathrm{~m}^{-3}$, which is much too small to have any discernible effect on neither the positive ion nor the electron density, a result also obtained by Reid (1990). Also the model calculation by Balsiger et al. (1996) show that a mixing ratio of 1 ppmv leads to a small increase in the positive ion density, not a large decrease as observed, when the particles are assumed to be of NLC size.

The positive ion density is determined by the balance between the production rate $Q_{i}$ and electron-ion recombination and ion attachment to aerosol particles. The attachment rate per unit volume is proportional to the total area of the particles in that volume. Keeping the water mixing ratio (in the ice phase), $w$, fixed and assuming that all particles have the same radius $r_{a}$, the attachment rate is $\psi_{i, Z} n_{a, Z} \propto \frac{w}{\rho_{a}} \frac{1}{r_{a}}$,

where $\rho_{a}$ is the particle mass density, showing that sharing the available moisture between many small particles maximises the surface area. However, because the rate only varies as the inverse first power of the particle radius, decreasing the particle size from 50 to $1 \mathrm{~nm}$ "only" gives a 50fold increase in surface area. Maintaining the aerosol surface area of Fig. 6 in that case, $w$ would still be 10-20 times higher than observed values. Moreover, the aerosol particle density would then be of order $10^{13} \mathrm{~m}^{-3}$. The aerosol particle density is limited by the number of available condensation nuclei. Although the density of smoke particles, assumed to be the condensation nuclei, is uncertain, model calculations seem to preclude densities higher than $10^{11} \mathrm{~m}^{-3}$, even for sub-nm particles (e.g. Hunten et al., 1980; Megner et al., 2008).

Another alternative to reconcile water vapour measurements with model requirements, is that the mesospheric ice particles are not solid, spherical ice particles with a mass density similar to water ice at $1 \mathrm{~atm}$ pressure, as we have assumed, but rather very "fluffy" particles with a much larger ratio of the particle surface area to mass. For this effect to explain the measured ion density depletion, the particle surface area would have to be at least of order 100 times larger than the area of a spherical particle with the same mass. One could also imagine that the particles were only covered with a thin surface layer of ice on top of a core of, e.g., silicate material. This possibility seems unlikely, though, since we must then have a high number density of large (tens of $\mathrm{nm}$ ) smoke particles on which water vapour condenses.

The reduction in $n_{i}$ is more easily achieved by reducing the recombination rate $\alpha$ to the value applicable to $\mathrm{NO}^{+}$, $\alpha=\alpha_{m}$, in which case even $2 \mathrm{~nm}$ particles (albeit with a very high number density) could produce the measured reduction in $n_{i}$ (Fig. 4). The water mixing ratio, being not more than 10 ppmv even in the $10 \mathrm{~nm}$ case of Fig. 7, is in approximate agreement with water vapour measurements. And with a combination of large particles and a small value for $\alpha$ the reduction in $n_{i}$ can be achieved with even lower aerosol particle densities; Fig. 8 shows that a particle density of order $5 \times 10^{8} \mathrm{~m}^{-3}$ is sufficient (although it still leads to a water mixing ratio of order $50 \mathrm{ppmv}$ ).

The high required density of NLC-sized particles, particularly with $\alpha=\alpha_{c}$, also exceeds lidar measurements of typical NLC number densities, which are not much higher than $1 \times 10^{8} \mathrm{~m}^{-3}$ (Baumgarten and Fiedler, 2008).

Unfortunately we have no information about the ion species present in the particle layer. The rocket described by Balsiger et al. (1996), however, carried an ion mass spectrometer. It showed unequivocally that where the reduction in ion density occurred, around $83-84 \mathrm{~km}$ and $82.5-86 \mathrm{~km}$ during ascent and descent, respectively, the dominant ions were definitely water cluster ions $-\mathrm{O}_{2}^{+}$and $\mathrm{NO}^{+}$only appeared 
above $85 \mathrm{~km}$, and the transition from water cluster to molecular ions occurred at $89 \mathrm{~km}$. They detected approximately a factor 100 reduction in $n_{i}$ inside the NLC layer, while the reduction seen in Fig. 2 is at least a factor 2. Hence Balsiger et al. detected a very strong reduction in the positive ion density in a region where our chosen large value, $\alpha=\alpha_{c}$, corresponding to water cluster ions, should be applicable. If their measurement of ion composition is also relevant to the ECOMA-3 flight, our recombination rate $\alpha$ is probably rather too small than too large, as we have assumed that the transition to molecular ions takes place gradually between 82 and $88 \mathrm{~km}$, implying that in the particle layer around $86 \mathrm{~km}$ the rate is already reduced to about $1 / 3$ of the value assumed for water cluster ions. This is corroborated by the MASS rocket observations, where a ledge in the aerosol particle measurements indicate that the transition occurred at $88 \mathrm{~km}$ (Robertson et al., 2009). Based on many rocket flights, Friedrich and Torkar (1988) find that at the low temperatures of the summer mesopause the transition from cluster to molecular ions occurs at neutral densities of $1-2 \times 10^{20} \mathrm{~m}^{-3}$, which, based on the CONE measurement, corresponds to an altitude range of approximately $85-86.5 \mathrm{~km}$ during the ECOMA-3 flight. Hence it is probable that the transition occurred in the middle of the particle layer, which adds uncertainty to the interpretation of the measurements.

Another uncertainty in our model is the electron-ion production rate $Q_{i}$. It was chosen based on our guess for the undisturbed electron and ion density in absence of aerosol particles (the dotted line in the left-hand panel of Fig. 4). At e.g., $86 \mathrm{~km}$ the assumed undisturbed density is $n_{0}=1.7 \times 10^{9} \mathrm{~m}^{-3}$, approximately a factor 10 larger than the density measured by Balsiger et al. (1996) just below the ion density depletion. With $\alpha=\alpha_{c}(z)$ we then deduce a production rate at this altitude $Q_{i} \approx 7 \times 10^{6} \mathrm{~m}^{-3} \mathrm{~s}^{-1}$, close to the value assumed by Reid (1990) but about 300 times larger than the value assumed by Balsiger et al.. In the models using $\alpha=\alpha_{m}$ (corresponding to $\mathrm{NO}^{+}$ions), $Q_{i} \approx 2 \times 10^{6} \mathrm{~m}^{-3} \mathrm{~s}^{-1}$. In our case the particle layer extends over almost $5 \mathrm{~km}$ and the choice of an undisturbed density is therefore not unambiguous. Had we chosen smaller values for $n_{0}, Q_{i}$ would be smaller, and a reduction in ion density could be achieved with a smaller aerosol particle density than we had to assume above. However, if we insist on a monotonically increasing plasma density with altitude in the absence of aerosol particles, $n_{0}$ cannot be reduced by a large factor and we shall still need a large number of aerosol particles.

The values for $Q_{i}$ we get when using the larger value of $\alpha=\alpha_{c}$ seem reasonable for the daytime mesopause region at a time of weak (or no) electron precipitation, while the values resulting from $\alpha=\alpha_{m}$ are too small to be compatible with a sunlit atmosphere (Reid, 1990; Rapp and Lübken, 2001). The solar zenith angle at the time of launch was $92^{\circ}$. It is therefore conceivable that a smaller value for $Q_{i}$ is acceptable. On the other hand, the fact that a significant number of positively charged smoke particles must have been present indicates that UV radiation was still present at the altitude of the particle layer.

Riometer data indicate that there must have been some electron precipitation at the time of the rocket flight, and that above the electron biteout region, at least, the electron-ion production rate $Q_{i}$ was definitely higher than accounted for by UV radiation alone. This is another indication (but no proof) that the larger values for $Q_{i}$, consistent with a high $\alpha \sim \alpha_{c}$, are appropriate.

In the models of Figs. 6, 7, and 8 we had to use a very large photoionisation rate for the $1.5 \mathrm{~nm}$ smoke particles, $I_{a}=10^{-2} \mathrm{~s}^{-1}$, to produce the positively charged particles required by the measurements. A smaller photoionisation rate would lead to smoke particles with a net negative charge. The large smoke particle photoionisation rate required indicates that these may have a different chemical composition with a lower work function than the large ice particles, which is consistent with the assumption that meteor smoke has different properties than ice.

Photoemission from $\mathrm{Na}$ adsorbed on ice films has been studied in the laboratory, showing that even a tiny amount of $\mathrm{Na}$ is sufficient to dramatically reduce the photoemission threshold (Vondrak et al., 2006). The same study also found that the photoionisation rate of an $\mathrm{Na}$ atom adsorbed on an ice particle in the mesosphere would be about $0.1 \mathrm{~s}^{-1}$, indicating that our required smoke particle photoionisation rate is not totally unrealistic if these particles contain Na. Lidar observations using the ALOMAR Na lidar at Andøya, show a complete absence of free $\mathrm{Na}$ atoms below about $87 \mathrm{~km}$ at the time of launch (B. Williams, personal communication, 2007). Many years of Na lidar measurements at this latitude have shown that the Na layer in August extends from $85 \mathrm{~km}$ to $100 \mathrm{~km}$, except in the presence of PMSE or NLC (von Zahn et al., 1988; Kurzawa and von Zahn, 1990; Hansen and Hoppe, 1996; She et al., 2006; Thayer and Pan, 2006). Gardner et al. (2005) have also demonstrated the rapid uptake of $\mathrm{Na}$ on NLC and PMSE particles, in this case at high southern latitudes in summer.

The influx of $\mathrm{Na}$ into the mesopause region by meteors is at least $1.6 \times 10^{7} \mathrm{Na}$ atoms/( $\mathrm{s} \mathrm{m}^{2}$ ) (Kane and Gardner, 1993). This continuous influx can on average supply one new $\mathrm{Na}$ atom to each of the approximately $3 \times 10^{12}$ aerosol particles $/ \mathrm{m}^{2}$ observed (see Fig. 2 , right panel, assuming singly charged aerosols) every $2 \times 10^{5} \mathrm{~s}$, or every $55 \mathrm{~h}$. This compares well with the typical transport time of NLC particles poleward of $69^{\circ} \mathrm{N}$ of $36 \mathrm{~h}$ (Berger and von Zahn, 2007).

This argument, why high photoionisation rates are needed, assumes that the attachment rates for electrons and ions by aerosol particles (Eqs. 6-8) are also applicable to smoke particles. However, such particles are so small that they may be rather regarded as very large molecules for which these analytical expressions may not be appropriate. If the electron attachment rate is suppressed for very small particles, this could hypothetically explain why they charge positively 
without needing a low work function. On the other hand, we do note that for the $1.5 \mathrm{~nm}$ smoke particles that we have assumed, Eq. (6) yields $\psi_{e, 0} \approx 6 \times 10^{-12} \mathrm{~m}^{3} \mathrm{~s}^{-1}$, which is quite similar to the electron-ion recombination rate coefficient $\alpha$ for water cluster ions, indicating that Eq. (6) may not be entirely unrealistic for small particles, and may even underestimate the attachment rate.

The plasma and aerosol particle measurements presented here show a layer of large $\left(r_{a}>2 \mathrm{~nm}\right)$ particles carrying a net negative charge, and positively charged, small $\left(r_{a}<2 \mathrm{~nm}\right)$ particles that were not detected but must have been present to account for the missing positive charge. The MASS rocket launched 30 min before ECOMA-3 provided direct evidence for these positively charged particles: The MASS instrument is a mass analyzer capable of measuring positive and negative aerosol particles separately, sorting them into bins of varying particle size. On upleg the rocket flew through a layer containing both NLC and PMSE. In the particle layer particles larger than $3 \mathrm{~nm}$ were negatively charged (no positive charges were seen above $3 \mathrm{~nm}$ ), particles between 1 and $2 \mathrm{~nm}$ were about evenly split between positively and negatively charged particles, while particles smaller than $1 \mathrm{~nm}$ were mostly positively charged (Robertson et al., 2009). Robertson et al. (2009) suggested another explanation than a high photoionisation rate for the presence of positively charged particles, namely that these were ice particles that had grown on positive ions as condensation nuclei. Because of the reduced electron density the particles had not been neutralised (or become negatively charged) by the time the rocket made its measurement.

The modelled aerosol particle densities of, e.g., Figs. 5, 7 , and 8 illustrate the need for a particle instrument that can distinguish between the various charge states and preferably also measure the density of neutral particles. When aerosol particle densities are higher than the undisturbed electron and ion density in the absence of aerosol particles (i.e. the profiles used as initial conditions for the model), most of the aerosol particles will remain neutral, and of those that do become charged the number of positively charged and negatively charged particles can be comparable. Hence a current measurement, such as made with the DC channel of the ECOMA instrument, will be "blind" to the actual number of aerosol particles present. Similarly, if particles are large the number of particles carrying more than one elementary charge may be significant. Under such circumstances we obviously cannot obtain the density by simply assuming that each particle carries a single negative (or positive) charge. Such an assumption is only valid if the aerosol particle density is much lower than the ambient plasma density (in which case the impact of aerosol particles on the ambient plasma is small) and the particles are small. Even in that case one would have to assume that either electron attachment or particle photoionisation dominates, lest the densities of positively and negatively charged particles become comparable.

\section{Conclusions}

The aerosol particle instrument on the ECOMA-3 flight of August 2007 detected a layer of particles larger than approximately $2 \mathrm{~nm}$ carrying a net negative charge. The simultaneous electron density measurement by Faraday rotation and positive ion measurement by the PIP showed a reduction of both the electron and positive ion density in the particle layer, located approximately between 83 and $87 \mathrm{~km}$. Between 85 and $87 \mathrm{~km}$ the phase change was below the detection limit of the Faraday instrument, which is consistent with a nearly complete electron biteout in this region. The net charge carried by electrons and ions was too small to match the negative aerosol charge density. Charge neutrality of the plasma therefore requires that positively charged, small $(\lesssim 2 \mathrm{~nm})$ particles must have gone undetected by all the charged particle instruments. This is supported by observations from the MASS rocket, launched $30 \mathrm{~min}$ before ECOMA-3, detecting positively charged particles smaller than about $1 \mathrm{~nm}$ (Robertson et al., 2009). Assuming these "smoke" particles to carry a single charge, their density must be at least $2 \times 10^{8} \mathrm{~m}^{-3}$.

We have used a numerical model, accounting for the charging of aerosol particles and interaction between aerosol particles and the ambient plasma, to study under what conditions both the reduction in positive ion density and positively charged smoke particles can be expected.

A reduction in positive ion density can only be achieved under somewhat "extreme" conditions, supporting observations showing that this is an unusual phenomenon. The ion density depends most sensitively on the electron-ion recombination coefficient, which in turn depends sensitively on the ion composition, and the number density and size of the aerosol particles. Since the ECOMA-3 rocket did not carry an ion mass spectrometer, the ion composition is not known. With a rate coefficient corresponding to a mixture of water cluster and molecular ions, the required density depletion can only be achieved with a large number of NLC-sized particles. Assuming these particles to be solid ice with a mass density comparable to ice at $1 \mathrm{~atm}$ pressure, their water content exceeds observed mesospheric water vapour mixing ratios by orders of magnitude and the particle density is also approximately a factor 10 higher than typical NLC values. Assuming a recombination rate coefficient corresponding to $\mathrm{NO}^{+}$, the ion depletion can be obtained assuming smaller particles and/or lower number densities, and without exceeding the observed water vapour mixing ratio by a large factor. If molecular ions were dominant in the particle layer, a very small electron-ion production rate is required, which is not compatible with a sunlit atmosphere or electron precipitation.

The model calculations show that without photoionisation the smoke particles would become negatively charged. A very high photoionisation rate, of order $10^{-2} \mathrm{~s}^{-1}$ or higher, is needed for the smoke particles to become positively charged, as required by observations and charge neutrality. This 
indicates that these particles may have a different chemical composition, with a lower work function, than the large ice particles.

Acknowledgements. This work was supported by the Norwegian Space Centre, the Research Council of Norway (grant 177295), the German Space Center (DLR-grant 50OE0301), and the Austrian Research Funds (grant 18560).

Topical Editor C. Jacobi thanks two anonymous referees for their help in evaluating this paper.

\section{References}

Balsiger, F., Kopp, E., Friedrich, M., Torkar, K. M., Wälchli, U., and Witt, G.: Positive ion depletion in a noctilucent cloud, Geophys. Res. Lett., 23, 93-96, 1996.

Baumgarten, G. and Fiedler, J.: Vertical structure of particle properties and water content in noctilucent clouds, Geophys. Res. Lett., 35, L10811, doi:10.1029/2007GL033084, 2008.

Baumgarten, G., Fiedler, J., Fricke, K. H., et al.: The noctilucent cloud (NLC) display during the ECOMA/MASS sounding rocket flights on August 3, 2007: Morphology on global to local scales, Ann. Geophys., in press, 2009.

Berger, U. and von Zahn, U.: Three-dimensional modeling of the trajectories of visible noctilucent cloud particles: An indication of particle nucleation well below the mesopause, J. Geophys. Res., 112, D16204, doi:10.1029/2006JD008106, 2007.

Bevilacqua, R. M., Schwartz, P. R., Bologna, J. M., Thacker, D. J., Olivero, J. J., and Gibbins, C. J.: An observational study of water vapor in the mid-latitude mesosphere using ground-based microwave techniques, J. Geophys. Res., 88, 8523-8534, 1983.

Blix, T. A.: The importance of charged aerosols in the polar mesosphere in connection with noctilucent clouds and polar mesosphere summer echoes, Adv. Space Res., 24, 1645-1654, 1999.

Friedrich, M. and Torkar, K. M.: Empirical transition heights of cluster ions, Adv. Space Res., 8, 235-238, 1988.

Gabrielli, P., Plane, J. M. C., Varga, A., Hong, S., Cozzi, G., Gaspari, V., Planchon, F. A. M., Cairns, W., Ferrari, C., Crutzen, P., Cescon, P., and Boutron, C. F.: Meteoric smoke fallout over the Holocene epoch revealed by iridium and platinum in Greenland ice, Nature, 432, 1011-1014, 2004.

Gardner, C. S., Plane, J. M. C., Pan, W., Vondrak, T., Murray, B. J., and $\mathrm{Chu}, \mathrm{X}$.: Seasonal variations of $\mathrm{Na}$ and Fe layers at the South Pole and their implications for the chemistry and general circulation of the polar mesosphere, J. Geophys. Res., 110, D10302, doi:10.1029/2004JD005670, 2005.

Hansen, G. and Hoppe, U.-P.: Investigation of the upper mesospheric dynamics under late polar summer conditions by EISCAT and LIDAR, J. Atmos. Terr. Phys., 58, 317-335, 1996.

Havnes, O.: Polar Mesospheric Summer Echoes (PMSE) overshoot effect due to cycling of artificial electron heating, J. Geophys. Res., 109, A02309, doi:10.1029/2003JA010159, 2004.

Havnes, O., La Hoz, C., and Næsheim, L. I.: First observations of the PMSE overshoot effect and its use for investigating the conditions in the summer mesosphere, Geophys. Res. Lett., 30, 2229, doi:10.1029/2003GL018429, 2003.

Havnes, O., Kassa, M., and La Hoz, C.: Time evolution of artificial electron heating in polar mesosphere summer echo layers, J. Geophys. Res., 112, D08202, doi:10.1029/2006JD007660, 2007.
Hill, R. J. and Bowhill, S. A.: Collision frequencies for use in the continuum momentum equations applied to the lower ionosphere, J. Atmos. Terr. Phys., 39, 803-811, 1977.

Horányi, M., Gumbel, J., Witt, G., and Robertson, S.: Simulation of rocket-borne particle measurements in the mesosphere, Geophys. Res. Lett., 26, 1537-1540, 1999.

Hunten, D. M., Turco, R. P., and Toon, O. B.: Smoke and dust particles of meteoric origin in the mesosphere and stratosphere, J. Atmos. Sci., 37, 1342-1357, 1980.

Kane, T. J. and Gardner, C. S.: Lidar observations of the meteoric deposition of mesospheric metals, Science, 259, 1297-1300, 1993.

Kurzawa, H. and von Zahn, U.: Sodium density and atmospherictemperature in the mesopause region in polar summer, J. Atmos. Terr. Phys., 52, 981-993, 1990.

Lie-Svendsen, Ø., Blix, T. A., Hoppe, U.-P., and Thrane, E. V.: Modelling the plasma response to small-scale aerosol particle perturbations in the mesopause region, J. Geophys. Res., 108, 8442, doi:10.1029/2002JD002753, 2003.

Love, S. G. and Brownlee, D. E.: A direct measurement of the terrestrial mass accretion rate of cosmic dust, Science, 262, 550553, 1993.

McNeil, J. W., Lai, S. T., and Murad, E.: Differential ablation of cosmic dust and implications for the relative abundances of atmospheric metals, J. Geophys. Res., 103, 10899-10911, doi: 10.1029/98JD00282, 1998.

Megner, L., Siskind, D. E., Rapp, M., and Gumbel, J.: Global and temporal distribution of meteoric smoke: A two-dimensional simulation study, J. Geophys. Res., 113, D03 202, doi:10.1029/ 2007JD009054, 2008.

Megner, L., Khaplanov, M., Gumbel, J., Baumgarten, G., Strelnikov, B., and Rapp, M.: Optical observation of an unusually high noctilucent cloud during the ECOMA/MASS campaign, Ann. Geophys., in press, 2009.

Natanson, G. L.: On the theory of the charging of amicroscopic aerosol particles as a result of capture of gas ions, Sov. Phys.Tech. Phys., 5, 538-551, 1960.

Pedersen, A., Trøim, J., and Kane, J. A.: Rocket measurements showing removal of electrons above the mesopause in summer at high latitude, Planet. Space Sci., 18, 945-947, doi:10.1016/ 0032-0633(70)90092-9, 1970.

Plane, J. M. C.: The chemistry of meteoric metals in the Earth's upper atmosphere, Int. Rev. Phys. Chem., 10, 55-106, doi:10. 1080/01442359109353254, 1991.

Rapp, M.: Capture rates of electrons and positive ions by mesospheric aerosol particles, J. Aerosol Sci., 31, 1367-1369, 2000.

Rapp, M. and Lübken, F.-J.: Modelling of particle charging in the polar summer mesosphere: Part 1 - General results, J. Atmos. Terr. Phys., 63, 759-770, 2001.

Rapp, M., Strelnikova, I., Strelnikov, B., Latteck, R., Baumgarten, G., Li, Q., Megner, L., Gumbel, J., Friedrich, M., Hoppe, U.P., and Robertson, S.: First in situ measurement of the vertical distribution of ice volume in a mesospheric ice cloud during the ECOMA/MASS rocket-campaign, Ann. Geophys., 27, 755-766, 2009, http://www.ann-geophys.net/27/755/2009/.

Reid, G. C.: Ice Particles and Electron "Bite-Outs" at the Summer Polar Mesopause, J. Geophys. Res., 95, 13891-13896, 1990.

Robertson, S. and Sternovsky, Z.: Effect of the induced-dipole force on the charging of aerosol particles, Phys. Plasmas, 15, 040702, 
doi:10.1063/1.2907162, 2008.

Robertson, S., Horányi, M., Knappmiller, S., Sternovsky, Z., Holzworth, R., Shimogawa, M., Friedrich, M., Torkar, K., Gumbel, J., Megner, L., Baumgarten, G., Latteck, R., Rapp, M., Hoppe, U.-P., and Hervig, M. E.: Mass analysis of charged aerosol particles in NLC and PMSE during the ECOMA/MASS campaign, Ann. Geophys., in press, 2009.

Schunk, R. W.: Mathematical Structure of Transport Equations for Multispecies Flows, Rev. Geophys. Space Phys., 15, 429-445, 1977.

Seele, C. and Hartogh, P.: Water vapour of the polar middle atmosphere: Annual variation and summer mesosphere conditions as observed by ground-based microwave spectroscopy, Geophys. Res. Lett., 26, 1517-1520, 1999.
She, C.-Y., Williams, B. P., Hoffmann, P., Latteck, R., Baumgarten, G., Vance, J. D., Fiedler, J., Acott, P., Fritts, D. C., and Lübken, F.-J.: Simultaneous observation of sodium atoms, NLC and PMSE in the summer mesopause region above ALOMAR, Norway (69 degrees N, 12 degrees E), J. Atmos. SolarTerr. Phys., 68, 93-101, 2006.

Thayer, J. P. and Pan, W. L.: Lidar observations of sodium density depletions in the presence of polar mesospheric clouds, J. Atmos. Solar-Terr. Phys., 68, 85-92, 2006.

von Zahn, U., Hansen, G., and Kurzawa, H.: Observations of the sodium layer at high latitudes in summer, Nature, 331, 594-596, 1988.

Vondrak, T., Plane, J. M. C., and Meech, S. R.: Photoemission from Sodium on Ice: A Mechanism for Positive and Negative Charge Coexistence in the Mesosphere, J. Phys. Chem., B 110, 3860 3863, 2006. 